\title{
REVISÃO INTEGRATIVA DAS PRODUÇÕES ACADÊMICAS SOBRE O CURSO DE EDUCAÇÃO FÍSICA NA MODALIDADE A DISTÂNCIA - EAD
}

\author{
Jitone Leônidas Soares \\ Universidade de Brasília, Brasília, Distrito Federal, Brasil
}

Ari Lazzarotti Filho

Universidade de Goiás, Goiânia, Goiás, Brasil

Jônatas de França Barros

Universidade Federal do Rio Grande do Norte, Natal, Rio Grande do Norte, Brasil

Patrick Ramon Stafin Coquerel

Universidade Federal do Rio Grande do Norte, Natal, Rio Grande do Norte, Brasil

André Ribeiro da Silva

Universidade de Brasília, Brasília, Distrito Federal, Brasil

\begin{abstract}
Resumo
Esta revisão integrativa analisou as produções científicas realizadas sobre a Educação Física a Distância, presentes nas bases indexadas no portal Periódicos da CAPES durante os anos de 2012 a 2016 a partir de 175 resultados encontrados no site. As buscas foram realizadas por meio do acesso remoto ao conteúdo assinado, a partir do acesso CAFe - Comunidade Acadêmica Federada, provido pela Rede Nacional de Ensino e Pesquisa (RNP) para instituições de ensino federadas, inclusive, para a Universidade de Brasília. Desta forma, observa-se a prevalência de estudos que abordam diferentes aspectos dos cursos de Educação Física a Distância, sendo estes pertinentes ao cotidiano das experiências apontadas.
\end{abstract}

Palavras-chave: Educação Física a Distância. Educação a Distância. EaD UnB.

\section{Introdução}

A Educação Física cresce cada vez mais em suas diferentes possibilidades e intervenções na sociedade contemporânea. Desde o seu nascimento com a formação de professores de Educação Física em 1929, até sua regulamentação em 1998, muitos desdobramentos ocorreram.

Conforme nos diz Pereira (2010), a Educação Física e suas manifestações estão em franco crescimento, tanto no campo científico quanto no campo fitness, ou, ainda, no contexto do mercado mundial esportivo. Há diferentes possibilidades de atuação no campo da Educação Física, possibilitando aos profissionais que atuam em espaços de intervenção ou na escola, nas pequenas e grandes cidades, a atuarem também como participantes de equipes e organizadores de eventos, tais como copa do mundo e jogos olímpicos.

Pereira (2010) nos diz que a Educação Física vem alcançando patamares nunca antes alcançados e por concordar com seus argumentos, destacamos um patamar em que a Educação Física chegou com a formação de profissionais por meio da Educação a Distância, pata- 
mar que representa a modalidade de ensino em constante desenvolvimento e que provavelmente irá desenvolver-se muito mais em uma projeção indefinida nos próximos anos.

Nesta última década, houve um crescimento considerável na oferta de cursos na modalidade a distância. Conforme nos informa Sales (2010), nos últimos anos houve um aumento de $247 \%$ no número de alunos regularmente matriculados em cursos de EaD credenciados no Brasil e que obteve, já em 2013, investimentos de aproximadamente 10 bilhões de reais. Sales (2010) expressa que os dados do Censo EaD.br mostram que 2,64 milhões de brasileiros estudaram por Educação a Distância em 2008, distribuídos em pelo menos 1.752 cursos. A autora destaca também que pelos dados do Ministério da Educação (MEC), no fim de 2009, o ensino a distância contava com 111 instituições de Educação Superior, sendo 52 particulares, 11 confessionais e 48 federais, estaduais e institutos federais.

Podemos perceber como é considerável o avanço da Educação a Distância na sociedade e a surpreendente evidência de como diversas áreas da ciência, estão se adaptando a essa nova modalidade de ensino. São inúmeras as iniciativas e programas que tem como objetivo a formação de novos profissionais, muitos deles licenciados para atuarem nas mais diferentes escolas públicas e particulares brasileiras, além de projetos nas mais diferentes inserções do campo de intervenção da Educação Física.

Observa-se que há uma expansão na oferta de cursos na modalidade a distância, entretanto, acredita-se que há aqueles que ainda apresentam algumas fragilidades, precariedades no trabalho docente e na oferta de disciplinas, haja vista que podem ofertar programas que demonstram intenções muito mais capitalistas do que compatíveis com o ensino ideal dos tópicos presentes em um determinado campo.

Desta forma, pode-se pensar também em contrapontos na modalidade de Educação a Distância, uma vez que a EaD ainda possui formações realizadas de forma inadequada, bem como impróprias para um determinado público. Portanto, cabe aos órgãos de regulação legislar sobre o tema, e aos interessados em ingressar nos cursos $\mathrm{EaD}$, antes de se inscreverem em vestibulares checarem informações sobre as instituições de ensino em sistemas de informações, tais como o E-MEC.

Para ilustrar a proposição dessas iniciativas, observamos o que nos diz Fernandes (2012) acerca do caso específico do programa Universidade Aberta do Brasil que se insere em uma política pública do Governo Federal que busca ampliar e interiorizar a oferta de ensino superior no país por meio da Educação a Distância. Uma vez que um número significativo de universidades se encontra na faixa litorânea do território nacional, fazendo-se necessário um esforço para o atendimento a populações tradicionalmente prejudicadas pela falta de políticas públicas voltadas para a educação.

Diante da inserção do programa Universidade Aberta do Brasil (UAB) em diferentes estados da federação brasileira, faz-se necessário expor a experiência da Faculdade de Educação Física da Universidade de Brasília, que remonta ao ano de 2004, conforme nos lembra Fernandes (2012). Naquela ocasião se construiu um projeto piloto, denominado Programa Pró-Licenciatura, vinculado ao Centro de Educação a Distância (CEAD-UnB), logo nesse processo, os profissionais daquele projeto desenvolveram capacidades técnicas ligadas à formação de tutores e à produção de materiais didáticos. Vale ressaltar que somente dois anos depois, a Faculdade de Educação Física da UnB também abriu vagas para o sistema Universidade Aberta do Brasil (UAB).

Considerando-se a relevância do curso de Educação Física ofertado na modalidade a distância, este estudo analisa, por meio de uma revisão integrativa, a produção científica sobre esta modalidade de educação.

Mendes (2008) reflete e explica que a revisão integrativa inclui a análise de pesquisas relevantes possibilitando a síntese do estado do conhecimento de um determinado assunto, além de apontar lacunas do conhecimento que precisam ser preenchidas com a realização de 
novos estudos. Para o autor, este método de pesquisa permite a síntese de múltiplos estudos publicados e possibilita conclusões gerais a respeito de uma particular área do conhecimento. Mendes (2008) comenta que a revisão integrativa é um método valioso, pois em algumas áreas muitas vezes os profissionais não têm tempo para realizar a leitura de todo o conhecimento científico disponível, como, por exemplo, na área da enfermagem. Assim, segundo o autor, a revisão integrativa que facilita a interpretação de estudos que poderão lhe auxiliar na tomada de decisões e reflexões sobre conteúdos diferenciados.

\section{Método}

Foi realizado como método um dos recursos da Prática Baseada em Evidências, a revisão integrativa da literatura (GALVÃO; SAWADA; TREVIZAN, 2004). Este estudo é uma revisão integrativa dos últimos quatro anos, relacionada à produção cientifica do campo da Educação Física ofertada na modalidade a distância. De acordo com o objetivo do estudo e conforme estabeleceram Puccia e Mamede (2012) optou-se por este tipo de revisão de literatura, pois esta possibilita a incorporação de evidências sistematizadas por especialistas, de forma a construir um corpo de conhecimento sobre um determinado tema de relevância científica, neste caso a Educação Física modalidade a distância.

Puccia e Mamede (2012) orienta que o processo de revisão sistematizada pode ser produzido em seis fases distintas, sendo que a primeira corresponde à elaboração da pergunta norteadora: "Qual o quantitativo de produções cientificas relacionadas a Educação Física modalidade a distância?

Considerando as intervenções de Puccia e Mamede (2012) a segunda fase do trabalho é a amostragem na literatura, que procura incluir a maior variedade possível de estudos identificados, de forma a garantir a diversidade e amplitude dos resultados.

Desta forma, foi realizada a seleção de artigos no Portal Periódicos da CAPES/MEC que indexa diferentes bases científicas com variadas classificações propostas pela fundação CAPES. A busca no portal foi realizada por meio das seguintes combinações de palavraschave: "Educação Física a distância", "Pró-Licenciatura", "Educação Física UAB", e se baseou na adoção dos seguintes critérios de inclusão: a indexação de estudos nas respectivas bases de dados, no período compreendido entre 2012 a 2016; no idioma português, a partir de 176 resultados apresentados na base.

A terceira fase do estudo aconteceu pela coleta de dados utilizando uma tabela descritiva com os elementos: Autor, assuntos, data de publicação, idioma, identificado, fonte, título e características do estudo, sendo que a análise crítica dos estudos selecionados pode ser considerada à quarta fase do estudo.

Destaca-se que não foi realizada rejeição de estudos visto que o objetivo deste trabalho está pautado na soma quantitativa do maior número de achados relacionados à área da Educação Física. Podemos compreender que em um segundo momento, foi realizada uma verificação de estudos em sua totalidade afim de que fosse compilada uma listagem adequada, coerente e fidedigna de estudos já produzidos até o presente momento.

A seguir e conforme já destacou Puccia e Mamede (2012), a figura 1 apresenta os principais elementos do delineamento deste estudo no que se refere às fases de amostragem, coleta de dados e análise crítica dos estudos encontrados. As próximas fases, correspondentes à discussão dos resultados e apresentação da revisão integrativa podem ser consideradas a quinta e sexta fases respectivamente. 
Figura 1: Representação esquemática do delineamento do estudo, adaptado conforme exemplo de Puccia e Mamede (2012)

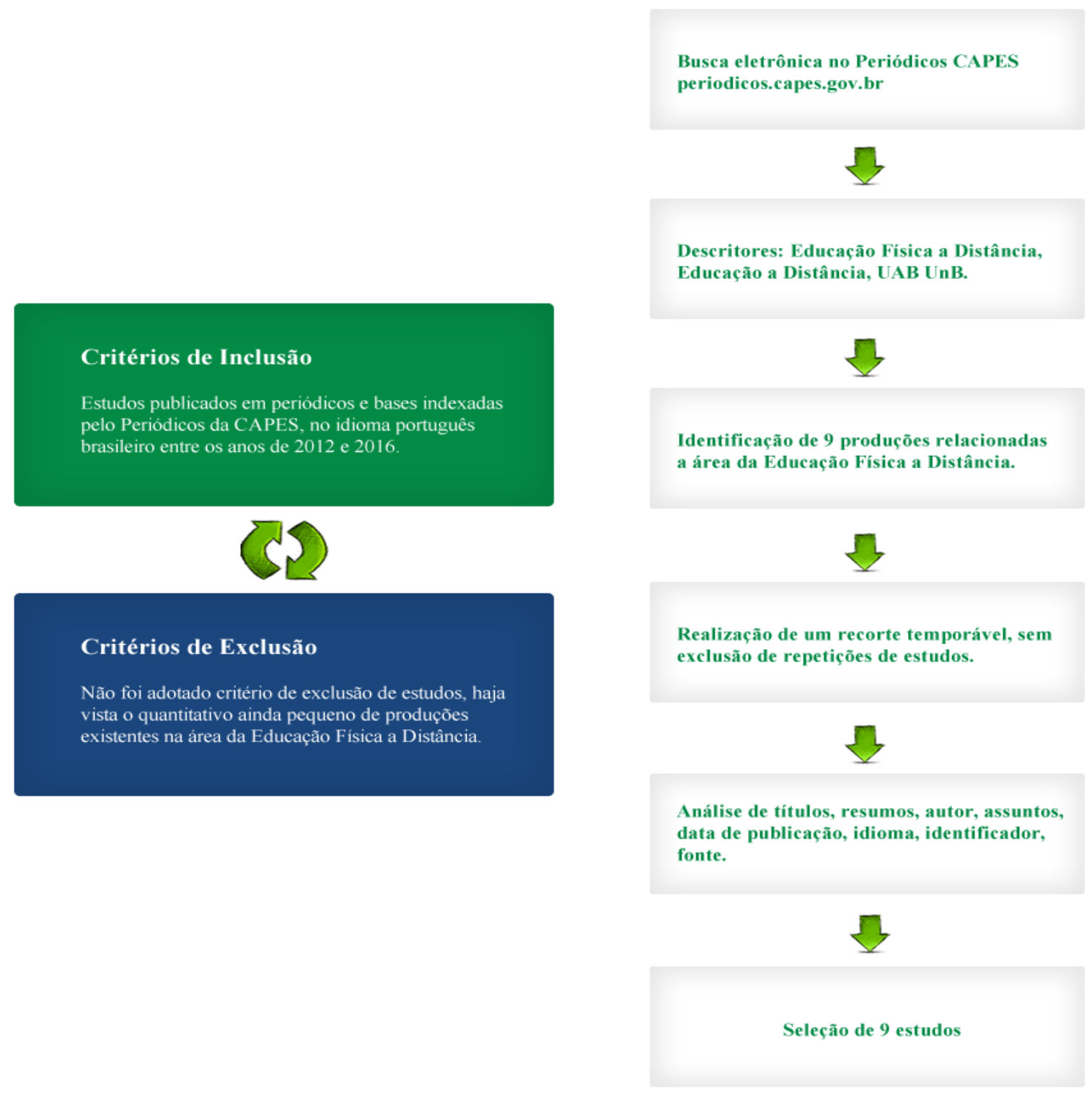

Fonte: Elaboração própria, 2016.

\section{Resultados e discussão}

Realizou-se uma revisão integrativa buscando agregar no Quadro 1 o maior número de estudos registrados sobre o curso de Educação Física na modalidade a distância. Pode-se compreender-se com esta revisão que os estudos da Educação Física a Distância ainda são incipientes, entretanto apresentam uma projeção considerável se observarmos o espaço de tempo em que foram publicados, ou seja, podemos supor que nos próximos anos tenhamos novas publicações apresentadas sobre a temática. 
Quadro 1: Estudos relacionados ao curso de Educação Física na modalidade a distância organizado segundo a estrutura: Autores, Assuntos, Idioma, Base de Dados, Título do estudo, Características do estudo e Fonte do estudo.

\begin{tabular}{|c|c|c|c|c|}
\hline & AUTORES/IDIOMAVBASE DE DADOS & TIITULO DO ESTUDO & $\begin{array}{c}\text { CARACTERISTICAS DO } \\
\text { ESTUDO }\end{array}$ & $\begin{array}{l}\text { FONTE DO } \\
\text { ESTUDO }\end{array}$ \\
\hline 1 & $\begin{array}{l}\text { Autor: Lazzarotti Filho, A. et al. } \\
\text { Idioma: Inglês } \\
\text { Base de dados: ScienceDirect (Elsevier) }\end{array}$ & $\begin{array}{c}\text { Saberes e práticas corporais } \\
\text { na formação de professores } \\
\text { de Educação Física na moda- } \\
\text { lidade a distância }\end{array}$ & $\begin{array}{c}\text { Identificar como o conheci- } \\
\text { mento de práticas corporais } \\
\text { em um curso de Educação } \\
\text { Física a distância. }\end{array}$ & $\begin{array}{c}\text { Revista Brasileira de } \\
\text { Ciências do Esporte, } \\
2013\end{array}$ \\
\hline 2 & $\begin{array}{c}\text { Autor: Silva, M. Z. } \\
\text { Idioma: português } \\
\text { Base de dados: Biblioteca Digital Brasileira } \\
\text { de Teses e Dissertações da UnB }\end{array}$ & $\begin{array}{l}\text { A mediação pedagógica no } \\
\text { ambiente virtual de aprendi- } \\
\text { zagem: análise dos fóruns do } \\
\text { curso a distância de educa- } \\
\text { ção física }\end{array}$ & $\begin{array}{l}\text { Analisa a mediação pedagó- } \\
\text { gica e a interação na interfa- } \\
\text { ce do Ambiente Virtual de } \\
\text { Aprendizagem }\end{array}$ & $\begin{array}{l}\text { Dissertação de } \\
\text { mestrado: Universi- } \\
\text { dade de Brasília, } \\
2013\end{array}$ \\
\hline 3 & $\begin{array}{c}\text { Autor: Amaro, R. } \\
\text { Idioma: Português } \\
\text { Base de dados: Biblioteca Digital Brasileira } \\
\text { de Teses e Dissertações (BDTD/IBICT) }\end{array}$ & $\begin{array}{c}\text { Mediação Pedagógica online } \\
\text { (sic): análise das funções do } \\
\text { tutor na Universidade Aberta } \\
\text { do Brasil }\end{array}$ & $\begin{array}{l}\text { Investiga a mediação peda- } \\
\text { gógica on-line com foco na } \\
\text { análise das funções do tutor } \\
\text { na Universidade Aberta do } \\
\text { Brasil - UAB }\end{array}$ & $\begin{array}{l}\text { Dissertação de } \\
\text { mestrado: Universi- } \\
\text { dade de Brasília, } \\
2012\end{array}$ \\
\hline 4 & $\begin{array}{c}\text { Autor: Melani, N. T. D. Z. } \\
\text { Idioma: Português } \\
\text { Base de dados: Biblioteca Digital Brasileira } \\
\text { de Teses e Dissertações - UnB } \\
\text { (BDTD/IBICT) }\end{array}$ & $\begin{array}{l}\text { Tutoria na educação a dis- } \\
\text { tância: um estudo sobre a } \\
\text { função pedagógica do tutor }\end{array}$ & $\begin{array}{l}\text { Conhecer e analisar como se } \\
\text { efetiva a função pedagógica } \\
\text { do tutor a distância em três } \\
\text { disciplinas do curso de Edu- } \\
\text { cação Física a distância. }\end{array}$ & $\begin{array}{l}\text { Dissertação de } \\
\text { mestrado: Universi- } \\
\text { dade de Brasília, } \\
2013\end{array}$ \\
\hline 5 & $\begin{array}{c}\text { Autor: André M. Q. et al. } \\
\text { Idioma: Português } \\
\text { Base de dados: Directory of Open Access } \\
\text { Journals (DOAJ) }\end{array}$ & $\begin{array}{l}\text { Histórias de vida e experiên- } \\
\text { cias docentes no estágio } \\
\text { supervisionado de licencian- } \\
\text { dos em Educação Física - } \\
\text { modalidade EAD }\end{array}$ & $\begin{array}{l}\text { Foi investigado um } \\
\text { aspecto específico da forma- } \\
\text { ção de professores de Educa- } \\
\text { ção Física na modalidade a } \\
\text { distância. }\end{array}$ & $\begin{array}{l}\text { - Revista Movimento, } \\
2013\end{array}$ \\
\hline 6 & $\begin{array}{c}\text { Autor: Amaro, R. } \\
\text { Idioma: Português } \\
\text { Base de dados: Repositório Científico de } \\
\text { Acesso Aberto de Portugal }\end{array}$ & $\begin{array}{c}\text { Licenciatura em Educação } \\
\text { Física a distância no Brasil: } \\
\text { um panorama da formação } \\
\text { de professores }\end{array}$ & $\begin{array}{l}\text { O estudo apresenta a experi- } \\
\text { ência de formação de profes- } \\
\text { sores de Educação Física a } \\
\text { distância no Brasil }\end{array}$ & $\begin{array}{l}\text { III Colóquio Luso- } \\
\text { - Brasileiro De Edu- } \\
\text { cação a Distância e } \\
\text { Elearning, } 2013\end{array}$ \\
\hline 7 & $\begin{array}{c}\text { Autor: Silva, A. R. et al. } \\
\text { Idioma: Português } \\
\text { Base de Dados: Repositório Cientifico de } \\
\text { Acesso Aberto de Portugal }\end{array}$ & $\begin{array}{c}\text { Utilização das ferramentas } \\
\text { da Web } 2.0 \text { pelos alunos do } \\
\text { curso de Educação Física a } \\
\text { distância da Universidade de } \\
\text { Brasília }\end{array}$ & $\begin{array}{l}\text { O estudo descreve qual o } \\
\text { nível de utilização pelos } \\
\text { alunos e incentivo do curso } \\
\text { para o uso das ferramentas } \\
\text { da WEB } 2.0\end{array}$ & $\begin{array}{l}\text { III Colóquio Luso- } \\
\text { Brasileiro De Edu- } \\
\text { cação a Distância e } \\
\text { E-learning, } 2013\end{array}$ \\
\hline 8 & $\begin{array}{c}\text { Autor: Jaeger, A. A. et al. } \\
\text { Idioma: Português } \\
\text { Base de dados: Repositório Científico de } \\
\text { Acesso Aberto de Portugal }\end{array}$ & $\begin{array}{l}\text { Educação física infantil e } \\
\text { anos iniciais: o desafio da } \\
\text { formação continuada à dis- } \\
\text { tância }\end{array}$ & $\begin{array}{c}\text { O estudo apresenta o curso } \\
\text { de Especialização em Educa- } \\
\text { ção Física Infantil e Anos } \\
\text { Iniciais na modalidade à } \\
\text { distância que é inédito no } \\
\text { Brasil. }\end{array}$ & $\begin{array}{l}\text { - III Colóquio Luso- } \\
\text { Brasileiro de Educa- } \\
\text { ção a Distância e } \\
\text { Elearning, } 2013\end{array}$ \\
\hline 9 & $\begin{array}{c}\text { Autor: Pimentel, F.C. } \\
\text { Idioma: Português } \\
\text { Base de dados: Biblioteca Digital Brasileira } \\
\text { de Teses e Dissertações - UnB } \\
\text { (BDTD/IBICT) }\end{array}$ & $\begin{array}{l}\text { A expansão de cursos de } \\
\text { Licenciatura em Educação } \\
\text { Física na modalidade a dis- } \\
\text { tância através do Sistema } \\
\text { Universidade } \\
\text { Aberta do Brasil }\end{array}$ & $\begin{array}{l}\text { O trabalho procura mostrar } \\
\text { as facetas da expansão dos } \\
\text { cursos de Licenciatura em } \\
\text { Educação Física no contexto } \\
\text { do Sistema Universidade } \\
\text { Aberta do Brasil (UAB). }\end{array}$ & $\begin{array}{l}\text { Dissertação de } \\
\text { mestrado; Universi- } \\
\text { dade de Brasília, } \\
2013\end{array}$ \\
\hline
\end{tabular}

Fonte: Elaboração própria, 2016. 
Observa-se um quantitativo relevante de estudos relacionados ao campo da Educação Física modalidade a distância, o que nos orienta a compreender que o campo apresenta dados relevantes que necessitam ser explorados. Os mais variados estudos apresentam considerações diversas que possibilitam uma compreensão diferenciada sobre os variados interesses que fazem parte da composição das estruturas características da Educação Física a Distância.

Partindo para um contexto de análise crítica dos estudos apontados, compreendemos que as práticas corporais apontadas por Lazzarotti filho et al. (2010) na formação de professores de educação física podem relacionar-se consideravelmente bem, com os ambientes de Educação a Distância. Haja vista que a formação por meio da EaD se consolida como uma ação efetiva quando transmite de forma adequada as intenções favoráveis as práticas reais pertinentes ao ambiente de intervenção do profissional do campo. Desta forma, compreendemos o estudo como uma intervenção que apresentou achados importantes para o contexto da formação do profissional durante o estágio supervisionado.

Silva (2012), por sua vez faz uma abordagem importante no contexto da Educação Física na modalidade a distância, pois analisa a mediação pedagógica e a interação, as diferentes possibilidades midiáticas, a organização das disciplinas na interface do Ambiente Virtual de Aprendizagem Moodle, bem como os fatores determinantes para a ocorrência da mediação entre os atores envolvidos no processo de ensino e aprendizado.

A autora reflete sobre o curso de Educação Física na modalidade a distância e no tocante às categorias de mediação e interação dos sujeitos diz que este não conseguiu romper com o antigo modelo das escolas de correspondência, fortemente caracterizado pelo baixo diálogo e por poucas possibilidades dos usos de recursos midiáticos e das Tecnologias de Informação e Comunicação (TIC). Assim, entendemos que os direcionamentos são favoráveis, mas ainda relacionados de forma insuficiente a orientação pelo bom diálogo e a utilização de diferentes mídias que favoreçam o contexto do cenário em que o curso está presente. Também é incipiente e necessita de direcionamentos específicos e precisos que contribuam significativamente para uma mudança necessária e importante para a busca constante da qualidade da formação oferecida no curso de Educação Física na modalidade a distância da Universidade Federal de Goiás.

Amaro (2012) apresenta uma investigação qualitativa acerca da mediação pedagógica on-line, com foco direcionado para a análise das funções do tutor na Universidade Aberta do Brasil - UAB, no contexto do ambiente virtual de aprendizagem, observando as funções pedagógicas do tutor no Curso de Licenciatura em Educação Física da Universidade de Brasília (UnB) na modalidade a distância.

A autora apresenta pensadores importantes que definem a interação, item indispensável na mediação pedagógica a partir de diferentes composições, uma vez que Martins e Cruz (2010) nos confirmam que a interação nada mais é que a ação recíproca entre sujeitos, midiatizadas por diferentes meios.

Gutierres e Pietro (1994) apresentam considerações relevantes sobre mediação pedagógica que se encaixam de forma coerente no cenário desejável para o curso de Educação Física na modalidade a distância, isto é, o processo de mediação pedagógica se concretiza na forma de apresentar o conteúdo, tema ou tópico pertinente ao planejamento educacional realizado, afim de orientar quem está sendo mediado a coletar relacionar, organizar e discutir as informações.

Diante destes apontamentos, compreendemos a mediação pedagógica como um processo fundamental de um curso a distância dependendo do modelo utilizado em seu planejamento, entretanto, para o contexto do curso de Educação Física modalidade a distância os professores precisam ser formados adequadamente para atuação, além de motivados para o cumprimento de suas intervenções pedagógicas de forma satisfatória e em tempo hábil com a qualidade desejada para o contexto em que a formação do campo da Educação Física exige. 
Melani (2013) desenvolveu um estudo que teve como propósito conhecer e analisar como se efetiva a função pedagógica do tutor a distância em três disciplinas do curso de Educação Física, visando a identificar a função pedagógica do tutor em três atividades do ambiente virtual de aprendizagem sendo o chat, fórum e tarefas-feedbacks além de possíveis implicações que estas refletiram no trabalho da tutoria.

Esta pesquisa apresenta conteúdos importantes que relacionam extratos de diferentes concepções de autores sobre os argumentos que justificam a intervenção pedagógica do tutor no curso de Educação Física na modalidade a distância. A partir destas colocações, apresentamos o que nos diz Moore e Kearsley (2007), sobre uma questão importante que merece atenção que é o monitoramento do processo de ensino, um requisito fundamental para êxito dos tutores e dos estudantes no curso de Educação Física da Universidade de Brasília na modalidade a distância.

Pensar em intervenções pedagógicas realmente impactantes se faz como uma preocupação constante a ser debatida nas discussões que permeiam as decisões de planejamento do curso de Educação Física na modalidade a distância, pois conforme nos informa Souza (2004), a relação pedagógica conclama a uma construção cotidiana, visto que, sozinho, o aprendiz caminha vacilante, perdendo o rumo desejado, porém o tutor pode ampará-lo, conduzi-lo e encaminhá-lo.

A partir destas considerações interpretemos o entendimento sobre as funções relativas as intervenções pedagógicas e compreendemos o cursista como um agente importante que carece ser desafiado, mas também que merece a atenção necessária para a sua ampla formação profissional e acadêmica.

Souza (2004) nos auxilia nas reflexões para a ampliação do debate sobre a intervenção pedagógica de tutores a distância e destaca se a educação é dialógica, é óbvio que o papel do professor, em qualquer situação, é importante, pois na medida em que ele dialoga com os educandos, deve chamar a atenção destes para um ou outro ponto menos claro, mais ingênuo, porém problematizando-os sempre.

Freire (1978) afirma que o papel do educador não é o de encher o educando com 'conhecimento', de ordem técnica ou não, mas sim o de proporcionar, através da relação dialógica educador-educando, educador-educador, a organização de um pensamento correto de ambos.

Quaranta e Pires (2013) elaboraram uma pesquisa que investigou o aspecto específico da formação de professores no que se refere ao estudo das histórias de vida na/com a Educação Física no ensino básico e as experiências docentes no primeiro estágio supervisionado de quatro cursistas do polo de apoio presencial da cidade de Piritiba - Bahia, do curso de licenciatura em Educação Física na modalidade a distância ofertado pela Universidade de Brasília no sistema Universidade Aberta do Brasil.

Compreende-se que a partir da implementação do programa UAB, podemos perceber a ampliação considerável das possibilidades para a formação profissional por meio da Educação a Distância. Cidadãos antes muito distantes das universidades públicas puderam formar-se por meio da internet, recebendo conteúdos planejados sob as mais diversas formas e por professores da Universidade de Brasília com diferentes níveis de formação.

Diversas políticas de ampliação do acesso à educação superior, mirando, sobretudo as licenciaturas, foram implementadas pelo governo federal, como por exemplo: o Programa Universidade Para Todos (PROUNI3) e o Programa de Apoio a Planos de Reestruturação e Expansão das Universidades Federais (GATTI E BARRETO, 2009).

O autor faz revelações importantes sobre o estudo de caso com os cursistas no estágio supervisionado e faz apontamentos sobre a importância da formação profissional para atuação do professor no magistério sendo que esta exige a compreensão de que ela se configura como um complexo processo multifacetado, em que tanto as histórias de vida dos cursistas, como 
suas experiências preliminares durante o curso de licenciatura em Educação Física a modalidade a distância são aspectos importantes, que vão somar-se àquelas decorrentes da sua inserção mais sistemática à cultura escolar, através do estágio supervisionado em que pode vivenciar e compreender as características consideráveis pertencentes ao espaço da escola (GATTI; BARRETO, 2009).

Dessa forma, reiteramos a "importância da criação de mecanismos de supervisão e acompanhamento mais próximo da cultura escolar por parte da instituição formadora e do seu polo presencial". Disponível em: <file///C:/Users/Periodicos/Downloads/23488-156391-1PB.pdf $>$ o que nos auxilia a compreender que tais aspectos são pontos fundamentais, passíveis de serem discutidos afim de possibilitarem a ampliação e reflexão sobre contextos que possam proporcionar uma formação profissional adequada, compatível com as necessidades do professor contemporâneo que lida com diferentes questões presentes no cotidiano escolar.

Refletindo sobre a formação do profissional no campo da Educação Física, Amaro (2013) apresentou um estudo que contextualizou a proposta do curso de Educação Física modalidade a distância por meio do sistema UAB no cenário brasileiro que, por meio de política pública, visava ampliar e democratizar a educação superior no país.

A autora fez uma abordagem do programa Universidade Aberta do Brasil, posicionando o leitor sobre as características do programa, no contexto da Universidade de Brasília. Destacamos argumentos extraídos do projeto político pedagógico do curso de Educação Física modalidade a distância por Amaro (2013), no que diz respeito ao egresso do curso sendo desejável que este tivesse condições

de aplicar nas escolas os conhecimentos e conteúdos vinculados aos aspectos da cultura do movimento humano, nas perspectivas da prevenção de problemas de agravo da saúde, promoção, proteção e reabilitação da saúde, da educação cultural, da educação e reeducação motora, do rendimento físico-esportivo, do lazer, da gestão de empreendimentos relacionados às atividades físicas, recreativas e esportivas, sendo que as bases práticas para as suas intervenções são o jogo, o esporte escolar, a ginástica, a dança, as lutas e o lazer (UnB, 2011).

Estes argumentos são plausíveis, uma vez que o profissional de Educação Física, deve obter conhecimento que lhe forme em sua totalidade complexa, permeada pelo conteúdo do currículo do curso a distância que possibilitam atuar, que lhe auxilie a realizar intervenções satisfatórias baseadas nas necessidades do campo e de sua comunidade.

Por fim, aceitamos como indispensáveis ao estudo as contribuições de Amaro (2013) que confirma a Educação a Distância no Brasil como uma modalidade de ensino importante que por suas peculiaridades, tem oportunizado uma ressignificação no campo de formação de professores brasileiros, em especial, os professores de Educação Física, sendo a EaD, enquanto modalidade de ensino, por meio da Universidade Aberta do Brasil um programa impactante que possibilita a ampliação do acesso ao ensino superior e contribui para a democratização do ensino superior quando se expande e chega a regiões longínquas de um país de dimensões continentais.

Para ampliar a percepção de conhecimento dos estudos já apontados sobre a Educação Física modalidade a distância, elencamos também a apresentação de Silva et al. (2013) que fazem apontamentos sobre a utilização dos recursos da Web 2.0 pelos estudantes do curso de Educação Física modalidade a distância da Universidade de Brasília.

$\mathrm{O}$ autor faz uma breve apresentação e destaca que a Web 2.0 surgiu como forma de descrever a segunda geração da internet - World Wide Web, onde se permite e privilegia um espaço de interação, de colaboração, de compartilhamento de informações e comunicação 
global, fomentando uma inteligência coletiva, assim como já destacou Pinto (2011) em outros estudos.

Neste estudo, Silva (2013) desenvolveu um instrumento de coleta de dados que elencou questões que buscavam mensurar qual o nível de utilização dos recursos Web 2.0 para realização das atividades do curso de Educação Física modalidade a distância, citando como exemplos Buscadores Google, ASK entre outros, além de sites, blogs ou Fotologs, Wikis (Wikipédia), Redes Sociais (Facebook, Orkut, Hi5, Twiter e outras mais). Dos diversos dados coletados, as inferências apontaram que $96 \%$ dos cursistas já utilizam a Web 2.0 em suas rotinas acadêmicas, sendo que Silva (2013) concluiu que os alunos do curso de Educação Física modalidade a distância da UnB em geral, estão explorando de forma satisfatória os recursos da Web 2.0, além da plataforma Moodle, um ambiente virtual de aprendizagem utilizado no curso, entretanto o autor destaca que apercepção dos alunos quanto ao não ou pouco incentivo da Universidade para a utilização das ferramentas da Web 2.0 ainda é alto, o qual deve ser revisto e discutido em reuniões pedagógicas e de planejamento do curso como um todo em sua estrutura organizacional.

A partir destas considerações, podemos compreender que as intenções em difundir contextos de utilização da Web 2.0 pelos cursistas, propostas pelo autor são consideráveis, entretanto, é necessário buscar um olhar crítico sobre a utilização potencial e adequada das possibilidades apresentadas afim de que os cursistas possam se apropriar de tais contextos com o objetivo de utilizá-los de forma coerente como fator que pode qualificar as suas intervenções pedagógicas e pessoais enquanto professores de Educação Física.

Prosseguindo na revisão integrativa, contemplamos Jaeger et al. (2013) que desenvolveram uma pesquisa sobre o curso de Especialização em Educação Física Infantil e Anos Iniciais na modalidade à distância que segundo os autores é inédito no Brasil.

Os autores apontaram que este curso a distância foi direcionado para professores com graduação em Educação Física, Pedagogia e áreas afins e buscou promover a formação continuada daqueles que atuavam, na Educação Infantil e nos anos iniciais do Ensino Fundamental, privilegiando uma visão global e interdisciplinar dos aspectos pertinentes a educação da criança, principalmente, os que consideram o movimento humano como um meio educativo.

Jaeger et al. (2013) foram pertinentes quando apontaram argumentos de Campos (2009) que refletiu que tanto a Educação Infantil quanto os anos iniciais do Ensino Fundamental, constituem-se em um período de intensas aprendizagens centradas na linguagem oral, na ampliação da coordenação motora fina e ampla, na construção de noções de identidade, na expressão corporal e reconhecimento do próprio corpo, na vivência da ludicidade e na criatividade ao brincar, entre outros, atravessam a constituem os primeiros anos de vida da criança.

Tais argumentos são de imensa importância para as discussões no campo da Educação Física ofertada na modalidade a distância, haja vista que os temas apontados percorrem os diferentes eixos presentes na matriz curricular do curso, o que corresponde a fatores essenciais, sendo conteúdos que devem obrigatoriamente fazerem parte da formação e serem compreendidos pelo professor de Educação Física que atua na escola e em espaços pertencentes ao seu campo.

Por fim e para complementar a revisão com o último estudo encontrado na base de dados Periódicos da CAPES, apresenta-se a pesquisa de Pimentel (2013) que estudou as características da expansão dos cursos de Licenciatura em Educação Física no contexto do Sistema Universidade Aberta do Brasil (UAB), buscando compreender a expansão de cursos, propondo uma pesquisa que identificou, compreendeu e analisou um panorama da oferta de cursos de Licenciatura em Educação Física na modalidade a distância, sendo que em seguida especificamente analisou a experiência do curso de Licenciatura em EF através do sistema UAB na UnB, apontando tendências de desenvolvimento na oferta de cursos de Licenciatura em Educação Física no contexto da política nacional de professores a distância e do Sistema UAB. 
Pimentel (2013) compreende que esta pesquisa possibilitou uma maior compreensão acerca da formação de professores de Educação Física na modalidade a distância possibilitando a ampliação do conhecimento e interesse público no processo de desenvolvimento da política pública do Sistema UAB que de certa forma nos últimos anos vem possibilitando um crescimento considerável das ofertas de cursos de ensino superior na modalidade a distância.

Pimentel (2013) fez considerações pertinentes sobre a estrutura do curso de Educação Física a Distância, apontando argumentos do Projeto Político Pedagógico, PPP (2009), destacando que os componentes curriculares do curso foram pensados em uma direção crítica, evitando a adaptação de um currículo que contribui para um saber desarticulado, instrumental, pragmático.

A partir destas reflexões, percebe-se que o curso ofertado na modalidade $\mathrm{EaD}$, apresentou alguma estrutura coerente que favoreceu uma adequada oferta aos seus cursistas, utilizando-se abordagens conceituais que parecem ser compatíveis com a formação do professor de Educação Física.

\section{Considerações finais}

A formação do profissional de Educação Física por meio da Educação a Distância é uma realidade e faz parte da rotina de diferentes instituições de ensino brasileiras, principalmente da Universidade de Brasília pioneira em seu desenvolvimento com polos em inúmeros estados brasileiros.

Portanto, este artigo de caráter epistemológico, quantitativo e qualitativo apresentou argumentos que responderam a revisão sistemática desenvolvida, cuja pergunta foi: "Qual o quantitativo de produções cientificas relacionadas a Educação Física modalidade a distância", organizando-se assim um quadro em que há predominância de 4 dissertações de mestrado, seguidas por 3 artigos científicos e 2 comunicações orais, não havendo teses de doutorado, sendo que tais estudos parecem compor uma circunstância propícia para reflexões sobre um campo que apresenta dados relevantes que necessitam ser explorados.

Dessa forma, revela-se que para ter-se uma difusão ampla de estudos realizados sobre referida temática, é necessário que o portal Periódicos CAPES seja atualizado para linguagens de programação de internet muito mais dinâmicas, que consigam abarcar ampla indexações para registros de novos estudos em um menor espaço de tempo, afim de, potencializar o sítio existente, bem como, favorecer os trabalhos de pesquisas por diferentes estudiosos. Esta crítica se faz como elemento construtivo, por perceber-se o potencial que os Periódicos da CAPES detém para a comunidade acadêmica e para a sociedade em geral, mas que perde-se em alguma essência, devido a sua estrutura interna de pesquisa pouco dinâmica, que ainda não indexou alguns estudos já publicados há pelo menos 06 meses.

Sugere-se, portanto, que em uma linha cronológica para os próximos anos, tenhamos mais registros indexados de estudos que tratem de tópicos pertencentes a Educação Física modalidade a distância brasileira. Espera-se que neste período de tempo e com interesse de estudiosos, tenha-se dissertações, teses e artigos publicados em periódicos categorizados nos mais variados estratos adotados pela CAPES, além de difusões que possam contribuir com o desenvolvimento e avanço da área. 


\title{
INTEGRATIVE REVIEW OF THE ACADEMIC PRODUCTIONS OF PHYSICAL EDUCATION MODE DISTANCE - EAD
}

\begin{abstract}
This integrative review analyzed the scientific production carried out on the Physical Distance Education, present in bases Indexed in Periódicos CAPES during the years 2012-2016 from 175 results contained on the site. The searches were conducted through remote access to subscribed content from the access CAFe - Federated Academic Community, provided by the National Network of Education and Research (RNP) for federal educational institutions, including the University of Brasilia. Thus, there is the prevalence of studies that address different aspects of physical education courses Distance, which are relevant to everyday experiences mentioned.
\end{abstract}

Keywords: Physical Education Distance, Distance Education, EaD UnB

\section{REVISIÓN INTEGRADORA DE LAS PRODUCCIONES ACADÉMICAS DE EDU- CACION FÍSICA MODALIDAD A DISTANCIA - EAD}

\section{Resumen}

Esta revisión integradora analizó la producción científica realizada en la educación a distancia física, presentes en bases indexadas en portal Periódicos da CAPES, durante los años 20122016 de 175 resultados contenidos en el sitio. Las búsquedas se realizaron a través de acceso remoto al contenido suscrito desde el CAFe - Comunidad Académica Federada, proporcionado por la Red Nacional de Educación e Investigación (RNP) para las instituciones educativas federales, incluyendo la Universidad de Brasilia. Por lo tanto, existe la prevalencia de los estudios que abordan diferentes aspectos de los cursos de educación física Distancia, que son pertinentes a las experiencias cotidianas mencionadas.

Palabras clave: Distancia Educación Física, Educación a Distancia, EaD UnB

\section{Referências}

AMARO, R. Mediação Pedagógica online: análise das funções do tutor na Universidade Aberta do Brasil. 2012. 85 f. Dissertação (Mestrado em Educação) - Faculdade de Educação, Universidade de Brasília, Brasília, 2012.

. Licenciatura em Educação Física a Distância no Brasil: um panorama da formação de professores. In: III COLÓQUIO LUSO-BRASILEIRO DE EDUCAÇÃO A DISTÂNCIA E ELEARNING, 3, 2013, Lisboa, Atas... Lisboa: Universidade Aberta. LEAD, 2014.

CAMPOS, M. M. Ensino Fundamental e os desafios da lei $\mathbf{n}^{\mathbf{0}}$ 11.274/2006: por uma prática educativa nos anos iniciais do ensino fundamental que respeite os direitos da criança à aprendizagem. In: BRASIL. Ministério da Educação. Salto para o futuro: anos iniciais do Ensino Fundamental. Ano XIX, nº 12, Setembro, 2009.

CENSO EaD. CensoEaD.BR - Relatório Analítico da Aprendizagem a Distância no Brasil, 2010. Disponível em: http://www.abed.org.br/censoead/CensoEaDbr0809 portugues.pdf> . Acesso em: 15 out 2014.

FERNANDES, M. L. B. (Org.). Trajetórias das Licenciaturas da UnB: EaD em foco. 1 ed. Brasília: Editora Universidade de Brasília, 2012. v. 1. 280p. (Volume 1). 
FILHO, A. L.; SILVA, A. M.; PIRES, G. L. Saberes e práticas corporais na formação de professores de Educação Física na modalidade a distância. Revista Brasileira de Ciências do Esporte, v. 35, n.3, p.701-715, 2013.

FREIRE, P. Considerações em torno do ato de estudar. In: Ação cultural para a liberdade e outros escritos. Rio de Janeiro: Paz e Terra, 1978.

GALVÃO, C. M.; SAWADA, N.O.; TREVIZAN, M. A. Revisão sistemática: recurso que proporciona a incorporação das evidências na prática da enfermagem. Rev Latino-am Enfermagem, v. 12, n. 3, p. 549-56, 2004.

GATTI, B. A.; BARRETO, E. S. S. Professores do Brasil: impasses e desafios. Brasília: UNESCO, 2009.

GUTIERREZ, F.; PRIETO, D. A mediação pedagógica: a educação a distância alternativa. Campinas: Papirus, 1994.

JARGER, A. A.; HATGER, M. Educação física infantil e anos iniciais: o desafio da formação continuada à distância. In COLÓQUIO LUSO-BRASILEIRO DE EDUCAÇÃO A DISTẨNCIA E ELEARNING, 3, 2013, Lisboa, Atas... Lisboa: Universidade Aberta. LEAD, 2014.

LAZZAROTTI FILHO, A.; SILVA, A. M.; ANTUNES, P. C.; SILVA, A. P. S.; LEITE, J. O. O termo práticas corporais na literatura científica brasileira e sua repercussão no campo da Educação Física. Movimento, 2010, 16(1):11-29.

MARTINS, A. S.; CRUZ, D. M. Comunicação e Interação na EaD. Open Learn Lab Space. 2010. Disponível em: 〈http://labspace.open.ac.uk/mod/resource/view.php?id=365576> Acesso em: $13 \mathrm{dez} 2015$.

MENDES, K. D. S.; SILVEIRA, R. C. C. P.; GALVÃO, C. M. Revisão integrativa: método de pesquisa para a incorporação de evidências na saúde e na enfermagem. Texto Contexto Enferm, 2008; 17(4): 758-64.

MELANI, N. T. D. Z. Tutoria na educação a distância: um estudo sobre a função pedagógica do tutor. 2013, 129 f. Dissertação (Mestrado em Educação) - Faculdade de Educação, Universidade de Brasília, Brasília, 2013.

MOORE, M. G.; KEARSLEY, G. Educação à distância: uma visão integrada. Tradução Roberto Galman. 2. ed. São Paulo: Thomson Learning, 2007.

PEREIRA, N. G. A relação entre satisfação e permanência de clientes enquanto consumidores de serviços: um estudo em academias de atividades físicas. 2010. Dissertação (Mestrado em Gestão do Esporte), Faculdade de Educação Física, Universidade de Brasília, Brasília, 2010.

PIMENTEL, F. C. A experiência da Universidade de Brasília no contexto de expansão da licenciatura em educação física por meio do Sistema Universidade Aberta do Brasil. 2013. 178 f. Dissertação (Mestrado em Educação Física) - Faculdade de Educação Física, Universidade de Brasília, Brasília, 2013. 
PINTO, M. J. T. A utilização de ferramentas Web 2.0 em contexto educativo - um estudo com professores do $1^{\circ}$ ciclo do ensino básico. Dissertação (Mestrado em Educação). Escola Superior de Educação de Paula Frassinetti, Porto, 2011.

PUCCIA, M. I. R.; MAMEDE, M. V. Revisão integrativa sobre a violência por parceiro íntimo na gestação. Revista Eletrônica de Enfermagem, 2012, 14(4), p. 944-56.

QUARANTA, A. M.; PIRES, G. L. Histórias de vida e experiências docentes no estágio supervisionado de licenciandos em Educação Física - modalidade EAD. Movimento, 2013, 19(2), 185.

SALES. D. EAD tem expectativa de crescimento para os próximos anos. Disponível em: < http://www2.abed.org.br/visualizaDocumento.asp?Documento_ID=555> Acesso em: 29 out 2015.

SILVA, M. Z. A mediação pedagógica no ambiente virtual de aprendizagem: análise dos fóruns do curso a distância de educação física. 2012. 97 f. Dissertação (Mestrado em Educação Física) - Universidade de Brasília, Brasília, 2012.

SILVA, A. R.; CARVALHO, C. R.; BARROS, J. F.; ALVES, E. D. Utilização das ferramentas da Web 2.0 pelos alunos do curso de educação física a distância da Universidade de Brasília. In: Colóquio Luso-Brasileiro de Educação a Distância e E-learning, 3, Lisboa, 2013. "Colóquio Luso-Brasileiro... Atas. Lisboa: Universidade Aberta. LEAD, 2014. p. 1-8

SOUZA, M. G. A arte da sedução pedagógica na tutoria em Educação a Distância. MECSEED-Proinfo, 2004.

UNIVERSIDADE DE BRASÍLIA. (2011). Educação Física a distância. Disponível em: $\langle$ http://www.unb.br/aluno_de_graduacao/cursos/educacao_fisica_a_distancia $>$. Acesso em: 29 nov 2015.

Recebido em: 22/02/2016

Revisado em: 21/09/2016

Aprovado em: 18/10/2016

Endereço para correspondência:

andrepersonalsaude@gmail.com

André Ribeiro da Silva

Universidade de Brasília

Campus Universitário Darcy Ribeiro

prédio Multiuso I Bloco A sala A1 43/5

Asa Norte

70910970 - Brasília, DF - Brasil

Caixa-postal: 04410 